\title{
DEVELOPMENT OF A NOVEL EMERGENCY NEONATAL INTUBATION FLOWCHART
}

By Dr S Jackson¹, Dr C Higgins ${ }^{1}$, Dr P Slevin¹, Dr J Lewis ${ }^{1}$, Dr A Walker²

1 Neonatal Intensive Care Unit, Daisy Hill Hospital, Newry, United Kingdom. Correspondence; S.Jackson99@doctors.org.uk

2 Neonatal Intensive Care Unit, Royal Maternity Hospital, Belfast, United Kingdom.

\section{Introduction}

In a neonatal emergency, if intubation is indicated, it is imperative the correct equipment is collected promptly. Currently no neonatal intubation equipment guide exists. The objectives of this study were to create a Neonatal Intubation Flowchart (NIF 1), test effectiveness of NIF 1 and make an improved NIF 2.

\section{Methodology}

A prototype NIF 1 was created. In a United Kingdom hospital, level 2 neonatal unit, a sample of $\mathbf{4 5}$ paediatric doctors, neonatal nurses and midwives were randomised to a control group or intervention group, and consented to partake in a low fidelity simulation. The intervention group utilised the NIF 1. The simulation scenario involved a term newborn neonate, who required emergency intubation and the participant was tasked to collect the intubation equipment. Both cohorts were familiarised with the simulation environment and resuscitation trolley. The equipment list can be viewed in Table 1 . The outcomes measured were percentage of equipment collected (PCE), time to collect equipment (TD) and amount of questions asked (QA).

Table 1; Complete Equipment List

\begin{tabular}{|c|c|c|}
\hline Endotracheal Tube & Lubricant & Forceps \\
\hline Stylet & Tape & Benzoin Tincture \\
\hline Laso-Gastric Tube & Stethoscope & $\mathrm{CO}_{2}$ Detector \\
\hline
\end{tabular}

\section{$\underline{\text { Results }}$}

The data from the simulation can be seen in Table 2.

Table 2; Results

\begin{tabular}{c|c|c|c|}
\hline & PCE (\%) & TD (Seconds) & QA \\
\hline Control & 59 & 90 (IQR: $70.5-$ & 121.5) \\
\hline Intervention & 87 & $\begin{array}{c}140 \text { (IQR: } 1 \text { (IQ9.5 - } \\
\text { 182) }\end{array}$ & 1 (IQR: 0 - 2) \\
\hline IQR: Interquartile & Range & &
\end{tabular}

IQR; Interquartile Range

\section{Discussion}

The NIF 1 cohort asked less questions and collected more equipment, however it took longer to collect the equipment. This demonstrates that the NIF 1 improves preparation for intubation. This is consistent with results of similar studies indicating improved collection of equipment, however these studies demonstrated no difference in time to collect the equipment ${ }^{1,2}$. The increase TD with the NIF 1, reflects a difference in our study design, with the end point parameter being when the participant indicated their perceived completion of task. This highlighted that the control cohort was unaware of what equipment is required for intubation.

The NIF 1 resulted in less QA. It is hypothesised that less unnecessary QA results in less distraction to the Intubator/Team Leader (I/TL). Distraction is an an important human factor variable which adds to cognitive load on I/TL, with implications on patient safety ${ }^{3}$.

\section{Conclusion}

The NIF 1 demonstrates improved intubation equipment preparation and less distracting question asked.

The improved NIF 2 can be viewed in Image 1.

\section{Image 1; Neonatal Intubation Flowchart 2} NASAL Neonatal Emergency Intubation Flowchart
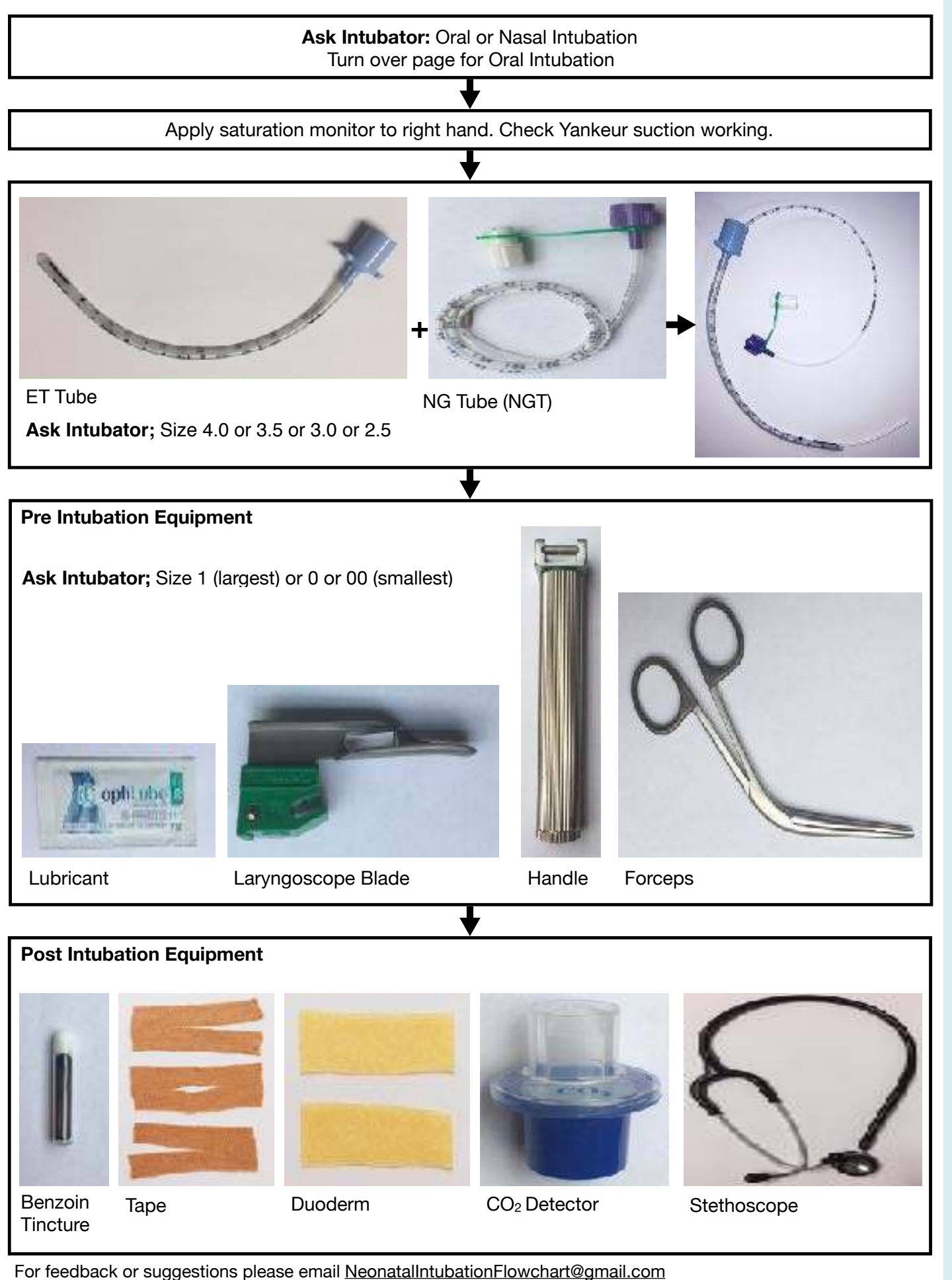